\title{
Ethnic Identity, Risk and Protective Factors Related to Substance Use Among Mexican American Students
}

Edward Codina, Zenong Yin, Jesse T. Zapata, and David S. Katims

This study examines the relationship between ethnic identity, risk and protective factors for substance use ,and academic achievement. Risk factors include deviant behavior and susceptibility to peer influence, while the protective factor is self-reported "confidence" not to use substances. The sample consists of 2,370 Mexican American students enrolled in eighth, ninth, and tenth grades. Results of the analysis (MANOVA) revealed that females had more positive ethnic identity than males. Furthermore, males were significantly more susceptible to peer influence, reported higher levels of deviant behavior, used more substances and had lower grade point averages than females. There was no significant difference in their "confidence" not to use substances.

A path analysis performed separately by gender 
revealed that positive ethnic identity was inversely related to peer susceptibility and deviant behavior. This relationship was stronger for females than for males. Ethnic identity was not directly related to substance use but rather the influence was indirect through its relationship to the risk factors. Findings related to academic achievement revealed that increased deviant behavior was negatively related to GPA. The total effect of a positive ethnic identity was significantly related to increased GPA for the females, but not for males.

Mexican American adolescents, due to their unique historical and current experience in the US, are exposed to risk and protective factors not common to members of the middle class majority. These unique risk and protective factors are related to the combination of class, culture, and ethnicity. Most Mexican Americans, for example, are found in working class segregated neighborhoods, have parents or grandparents who speak mostly Spanish, and are visibly identified as an ethnic minority (Codina and Montalvo 1994; Frey and Farley 1996).

Among the many psychological challenges faced by adolescence, the issue of identity formation becomes very salient during this stage (Erikson 1968). For Mexican Americans identity formation includes self-definition and awareness as members of an ethnic minority along with its social implications and consequences. Development of a strong positive self-identity may be problematic, as they struggle with differences in treatment based on their ethnic origin and social class. This conflict may negatively influence their identity formation and selfesteem. Erikson (1968) proposes that

... the individual belonging to an oppressed and exploited minority. . . [who] is aware of the dominant cultural ideals but prevented from emulating them, is apt to fuse the negative images held up to him by the dominant majority with the negative identity cultivated in his own group (303).

Mexican Americans may react to these conflicts in a variety of ways. Some may experience a loss of identity or 'identity confusion' (which can also be applied to ethnic identity). 
Identity loss and identity confusion have been recognized in severely conflicted young people "whose sense of confusion is due to a war within themselves and in confused rebels and destructive delinquents who war on their society" Erikson $(1968,17)$. Some may become involved in margina! identity and opposition cultural groups such as gangs. This issue has been described by Vigil (1988) based on his work among Mexican American adolescents gang members.

Other adolescents may embrace their ethnic identity with a positive affective evaluation. This ethnic pride generally includes a rejection of negative stereotypes about one's ethnic group (Kitano 1980) as well as positive attitudes and a sense of belonging and commitment to the ethnic group (Phinney and Rosenthal 1992). A positive ethnic identity appears to be a general protective factor in the development of minority adolescents. For example, several researchers have found a relationship between a positive ethnic evaluation and positive selfesteem among African Americans, Hispanics, and other "minority" adolescents (Roberts et al. 1996).

The literature examining the relationship between ethnic identity and risk factors for substance use is rather sparse. Cheung (1991) in a literature review of this issue concluded that many researchers assumed such a relationship but most did not include any ethnic identity measure in their studies. Research examining the relationship between a cultural identity and substance use has generally found an inverse relationship. For example Hispanic females with high cultural identity were less likely to use substances, particularly marijuana (Oetting and Beauvais 1990-91). Among Puerto Rican male adolescents, lower ethnic identification was related to participation in illicit substance use (Sommers, Fagan and Baskin 1993).

Several researchers have proposed that cultural identity may not be directly related to alcohol use but may be a mediating variable or may have indirect effects on substance use through risk and protective factors related to substance use (Felix-Ortiz and Newcomb 1995). Support for this hypothesis was found in a recent study of older adolescents in which a positive Puerto Rican identity was found to moderate the effects on substance abuse risk factors that include peer and 
family substance use attitudes and behaviors, personal substance use related behaviors, and drug availability (Brook et al. 1998). However, ethnic identity was not directly related to late adolescent drug use. The authors conclude that ethnic identity as a protective factor needs to be included in models related to reducing risk of substance use.

Ethnic identity and academic achievement-Matute-Bianchi (1989) has postulated that ethnic identity may promote academic achievement by buffering the psychological stress experienced by minority youth in white dominant school settings. These youth develop a support network comprised of similar others who promote acceptance and pride in one's ethnic culture. If the ethnic identity were viewed with a positive affective evaluation then ethnic identity would promote a positive selfview that encourages achievement. However, empirical research examining these relationships is very scant.

Efficacy and substance use-There has been some research that examined the relationship between self-efficacy and substance use among adolescents. Hays \& Ellickson (1990), for example, examined resistance efficacy that focused on adolescent feelings of being able to resist pressure to use drugs. They reported a high correlation between resistance efficacy and substance use. This resistance efficacy also seemed to be transferable across substances, although they may experience difficulty in different social settings. Using a more general construct of "cognitive self-efficacy" Scheier and Botvin (1996) reported efficacy to be inversely related to both general deviancy and polydrug use among eighth grade, urban, Black youth. However, research in this area is rather sparse.

Deviancy-There is a general agreement that there is a relationship between substance use and delinquency (Fagan, Weis and Cheng, 1990). Some researchers propose that individuals involved with drugs and deviant behavior have a general deviant orientation or involvement in a general deviant subculture. That is, both are influenced by a common set of causal variables and generally co-occur (Huizinga, Loeber and Thornberry 1993). For example, in a study that included Mexican American, white and black youth, Watts (1990) found that alcohol, tobacco, marijuana and other illegal drugs were related to both minor and violent delinquency for all three 
groups.

Substance use and academic achievement-In general, researchers have found a positive relationship between substance use and poor academic achievement using such measures as graduation from high school, self-reported grade point average, or educational aspirations (Beauvais et al. 1996). . This has also been found in research among Mexican American youth in which dropouts were found to have the highest rates of substance use, followed by those classified as atrisk students (Chavez, Edwards and Oetting 1989). However, other researchers have found much variation in the association between substance use and academic achievement in that some students perform academically better than expected, given their level of substance use, and others less well (Hundelby, Carpener and Mercer 1982).

Gender differences-Several researchers have noted that in general, there has been little research that specifically examines risk factors for males and females related to substance use (Khoury 1998). However, there is evidence that females internalize their emotional distress, resulting in depression, whereas males express their distress through socially deviant behavior (Horwitz and White 1987). Females also seem to be more susceptible to social influence to use substances and use of drugs to relieve emotional distress, including depression, than males (Opland, Winters, and Stinchfield 1995).

The present study was designed to examine the relationships among ethnic identity, self-reported deviancy, self-efficacy, substance use, and academic achievement. It was hypothesized that a positive ethnic identity was inversely related to deviancy and substance use while positively related to academic achievement. It was also hypothesized that deviancy was positively related to substance use and negatively related academic achievement, while confidence in not using substances was inversely related to substance use. The analysis was done separately by gender in order to be sensitive to any gender differences.

\section{Method}

\section{Subjects}

The school district in which the study took place compris- 


\section{Ethnic Studies Review Volume 24}

es a majority of Mexican American students whose characteristics are believed to be representative of the Mexican American population of the United States. The sample consists of 1,180 female and 1,190 male $(2,370)$ Mexican Americans students enrolled in eighth, ninth, and tenth grades from a south Texas, low socioeconomic status (SES), working-class school district. The students were surveyed in their schools in the spring of 1996. Reflective of the community characteristics, $64 \%$ of the children in the schools are on free or reduced fee lunch. Average property value for homes within the district range are estimated to be valued at $\$ 35,000$ and range from a low of $\$ 25,000$ to a high of $\$ 70,000$.

Only those students who identified themselves as Mexican American were used for the purpose of this study. The primary school language of all students surveyed was English.

\section{Survey Procedure}

A survey was administered to collect information in areas of students' deviant behavior, vulnerability to negative peer influence, use of substances, positive ethnicity identity, confidence to not use drugs, and self-reported grade point average.

Data were collected via a self-report questionnaire survey that was administered in fifty minutes. In order to control for standardized administration and readability of the survey, the survey was read aloud in English and students were directed to follow along. Trained university students administered the survey. No school personnel were present in the classroom during the administration.

\section{Instruments}

Ethnic identity-Ethnic identity was assessed using six items from the Mulitgroup Ethnic Identity Measure (Phinney and Rosenthal 1992). The measure includes items reflecting the degree of exploration and commitment of ethnic identity (e.g. "I have spent time trying to find out more about my ethnic/cultural group) and a sense of belonging and positive feelings toward the group ("I have a lot of pride in my ethnic/cultural group and its accomplishments"). Items are rated on a four-point scale ranging from strongly agree to strongly disagree. An ethnic identity score is derived by averaging the sum of the six items. 
The score can range from 0 (low ethnic identity) to 4 (high ethnic identity). The standardize alpha for this index is .80 .

Confidence not to use substances-These items are based on the self-efficacy scale of Protraska and DiClemente (Prochaska, DiClementi and Norcross 1992). The students were asked "How sure or confident are you that you would not use alcohol or drugs in each of the situations? -e.g. When feeling depressed." The responses included a) very sure not use, b) sure not use, c) might use. The individual items were recoded into either confident or not confident. The recoded items were summed and averaged. The scores were reversed so that higher scores reflect higher confidence. The Cronbach alpha was .90 for the scale.

Deviancy-this index is composed of twenty-two items related to "deviant" behavior (Yin, Katims, and Zapata 1999). The students were asked whether they have ever done any of the behaviors during the past year? Examples of the items include "cussed out loud at a teacher," "carried a knife to school," and "belonged to a gang." The responses were either a "yes" or "no." The items were summed and averaged. The alpha for this index is .91 .

Susceptibility to Peer Influence-Students were asked to indicate the degree to which their behavior is influenced by the behavior of close friends (Codina et al. 1998). A high score on this index indicated a high level of susceptibility to peer influence. The Cronbach's alpha was .68 for this seven-item index. Average grade-the students average grade was based on selfreport in which they were asked if their grades were "mostly A's" (score of 1), "mostly B's" (score of 2) or "mostly F's" (score of 5 ). The scores were reordered so that higher scores reflected higher average grades.

Substance use-The substance use index is composed of selfreported use of beer, wine, marijuana, or cigarettes in the last thirty days. The responses ranged from "never used in the last 30 days" (scored as " 0 ") to" used twenty times or more" (scored as "4"). The alpha for this index is .85 .

\section{Data Analysis}

First, Multivariate Analysis of Variance (MANOVA) was conducted by gender to examine differences in the risk and 
protective factors as well as the dependent variables. Significant gender difference would render further analyses to be performed separately for males and for females. To test the relationship between ethnic identity and substance use, academic achievement, an observed-variable path analysis was applied to fit the data to the hypothesized model using LISREL structural models separately by gender. Finally, gender invariance of the hypothesized model was examined using stacked LISREL models.

Model fit was assessed by examining various fit indices as suggested by Kelloway (1998). These included the Goodness of Fit Index (GFI) and the Adjusted Goodness of Fit Index (AGFI) that evaluates the absolute fit of the hypothesized model with the population covariance matrix. In addition comparative fit indices, the Normed Fit Index (NFI), the NonNormed Fit Index (NNFI), and the Comparative Fit Index (CFI), were also used to assess the improvment in fit of the hypothesized model compared to a baseline model. These indices range from 0 to 1, with values above .90 indicating a good fit of the data. The Root Mean Square Error of Approximation (RMSEA) is another important index. RMSEA indicates the amount of unfitted residuals between the implied and observed covariance matrices. Values less than .10 are interpreted as a good fit whereas values below .05 indicate a very good fit of the data. Chi-square (_) test was not used to assess the model since it is well known that it is too sensitive to sample size and data distribution.

In addition t-value associated with each estimate of the observed variable or relationship was used to assess whether it was adequately measured. A t-value was calculated by dividing its unstandardized estimate by its standard error. A value greater than 1.96 indicates the parameter was significantly different from zero, and therefore its dimensionality was correctly specified and fitted the data.

\section{Results}

Result of MANOVA-First, in order to examine the effect of gender on risk and protective factor and substance use and academic achievement variables, a one-way MANOVA on risk and protective factors and drug use was performed. The result 
revealed a significant gender main effect $(F[1,2,1174)=38.3$, $p$ <.000). Step-down F-test found that females had a higher positive sense of ethnicity than males ( $F[1,1174]=3.96, p<$. 05). On the other hand males were more likely to be involved in deviant behavior ( $F[1,1174]=109, p<.001)$, to be influenced by peer pressure ( $F[1,1174]=60$, p. <.000), to use drugs $(F[1,1174]=110, p<.001)$, and to have lower grades $(F[1,1174]=51, p<.001)$ than females. There was no significant gender difference in their confidence not to use drugs. Because of these gender differences further analyses were performed separately for male and females.

\begin{tabular}{|c|c|c|c|c|c|}
\hline \multirow[t]{2}{*}{ Variable } & \multirow{2}{*}{\multicolumn{2}{|c|}{$\begin{array}{c}\text { Males }(N=1,190) \\
M\end{array}$}} & \multicolumn{2}{|c|}{ Females $(N=1,180$} & \multirow{2}{*}{$\begin{array}{l}\text { ) } F \text { (sig.) } \\
(1,2,1174)\end{array}$} \\
\hline & & & M & SD & \\
\hline Ethnicity & 2.90 & 69 & 2.96 & .63 & $3.96(.05)$ \\
\hline $\begin{array}{l}\text { Susceptibility } \\
\text { Peer }\end{array}$ & 1.62 . & .57 & 1.46 & .46 & 109.6(.000) \\
\hline $\begin{array}{l}\text { Deviant } \\
\text { Behavior }\end{array}$ & 1.33 & .27 & 1.22 & .21 & $60.0(.000)$ \\
\hline
\end{tabular}

Confidence

Not Use

Drugs

Use of Drugs

1.69. .34

1.69

.33

$.03(.868)$

Grades

2.09. $\quad 1.3$

$1.61 \quad .92$

$110.0(.000)$

3.39. .97

$3.66 \quad .89$

$51.0(.000)$

Table 1. Means, Standard Deviations and Univariate $F$ Tests for Independent and Dependent Variables by Gender (MANOVA)

Result of Path Analysis-Table 2 displays the indices of model fit for male, female and stacked models. With the exceptions of AGFI and RMSEA other fit indices were all within acceptable ranges either for absolute or comparative fit suggesting data provided reasonable fit to the hypothesized relationships in both female and male models. Furthermore stacked path analysis clearly suggests that the relationships between risk and protective factors and drug use (i.e., the path coefficients) 
in the hypothesized model were similar between female and male students.

$X^{2}$ GFI AGFI RMSEA NFI NNFI CFI

\begin{tabular}{lccccccc}
\hline Female model & 465.58 & 95 & .80 & .28 & .96 & .89 & .96 \\
Male model & 519.19 & .95 & .77 & .29 & .96 & .88 & .96 \\
Stacked model & 1180.26 .94 & -.20 & .95 & .95 & .95 &
\end{tabular}

Table 2. Comparison of Indices of Overall Model Fit for the Hypothesized Model

Path Analysis for Female Students-For females a positive sense of ethnicity was inversely related to deviancy $(B=-.21$; $t=-6.49)$, peer susceptibility $(B=-.20 ; t=-6.22)$ and positively related to Confidence not Use Drugs $(B=.08 ; t=2.64)$. For females the total effect of a positive sense of ethnicity on lower drug use was significant $(B=-.13 ; t=-4.10)$. This relationship, however, is indirect rather than direct mainly through ethnic identity's relationship with deviant behavior and peer susceptibility. As hypothesized, confidence in not using substances was inversely related to drug use ( $B=-.29 ; t=-7.50)$ while deviant behavior $(B=.31 ; t=7.13)$ and peer susceptibility $(B=$ $.20 ; t=4.53$ ) were positively related to higher substance use. $A$ positive sense of ethnicity was significantly related to higher grades as indicated by its indirect effect $(B=.06 ; t=2.91)$ and total effect $(B=.22 ; t=2.63$ ) on grades

Path Analysis for Males-For males a positive ethnic identity was inversely related to deviancy $(B=-.11 ; t=-3.35)$ and peer susceptibility $(B=-.09 ; t=-2.80)$ but not to confidence not to use drugs (see Table 3 ). A positive sense of ethnicity was indirectly related to lower substance use $(B=-.06 ; t=-2.66)$ mainly through deviant behavior and peer susceptibility. Ethnic identity was also indirectly related to higher grades $(B=.03$; $t=2.48)$. Confidence in not using drugs $(B=-.24 ; t=-6.84)$ was directly related to lower substance use, while deviant behavior $(B=.28 ; t=7.16)$ and peer susceptibility $(B=.34 ; t=7.73$ ) were directly related to higher substance use. The total effect of 
deviant behavior on grades was also significant $(B=-.24 ; t=$ 2.06). The path analysis model showing the direct effects for males and females are presented in Figure 1.

\begin{tabular}{lllll}
\hline Outcome Variable & $\begin{array}{l}\text { Zero Spurious } \\
\text { Order }\end{array}$ & $\begin{array}{l}\text { Indirect } \\
\text { Effect } \\
\text { Beta(t) }\end{array}$ & $\begin{array}{l}\text { Direct } \\
\text { Effect } \\
\text { Beta(t) }\end{array}$ & $\begin{array}{l}\text { Total } \\
\text { Effect } \\
\text { Beta( } t)\end{array}$ \\
\hline
\end{tabular}

On Drug Use

$\begin{array}{lccccc}\text { Ethnicit } & -.13 & .00 & -.13(-5.57) & 00(-.14) & -.13(-4.10) \\ \text { Confidence } & -.57 & -.28 & - & -.29(-7.50) & -.29(-7.50) \\ \begin{array}{l}\text { Not Use Drugs } \\ \text { Deviant }\end{array} & & & & & \\ \begin{array}{l}\text { Behavior } \\ \text { Peer Suscept. }\end{array} & .60 & .29 & - & .31(7.83) & .31(7.83) \\ & .59 & .39 & - & .20(4.53) & .20(4.53)\end{array}$

On Grades

Behavior

$\begin{array}{llllll}\text { Ethnicity } & .22 & .00 & .06(2.91) & 16(1.94) & .22(2.63) \\ \text { Deviant } & -.29 & .-.06 & -.03(-.60) & -.20(-1.86) & -.23(-2.49)\end{array}$

$\begin{array}{llllll}\text { Drug Use } & -.24 & -.14 & - & -.10(-1.00) & -.10(-1.00)\end{array}$

Table 3. Effect Variables on Drug Use and Grades for Females

\begin{tabular}{|c|c|c|c|c|}
\hline Outcome Variable & $\begin{array}{l}\text { Zero Spurious } \\
\text { Order }\end{array}$ & $\begin{array}{l}\text { Indirect } \\
\text { Effect } \\
\text { Beta(t) }\end{array}$ & $\begin{array}{l}\text { Direct } \\
\text { Effect } \\
\text { Beta( } t)\end{array}$ & $\begin{array}{l}\text { Total } \\
\text { Effect } \\
\text { Beta }(t)\end{array}$ \\
\hline
\end{tabular}

\section{On Drug Use}

\begin{tabular}{|c|c|c|c|c|c|}
\hline Ethnicit & -.07 & .00 & $-.06(-2.66)$ & $00(-.22)$ & $-.07(-2.24)$ \\
\hline $\begin{array}{l}\text { Confidence } \\
\text { Not Use Drugs }\end{array}$ & -.59 & -.35 & 0 & $-.24(-6.84)$ & $-.24(-6.84)$ \\
\hline Devi & .64 & .36 & 0 & $.28(7.16)$ & $.28(7.16)$ \\
\hline ept & .67 & .33 & 0 & $.34(7.73)$ & $.34(7.73)$ \\
\hline
\end{tabular}

On Grades

$\begin{array}{lccccc}\text { Ethnicity } & .09 & .00 & .03(2.48) & 05(.71) & .09(1.17) \\ \text { Deviant } & -.31 & .07 & -.05(-1.78) & -.19(-1.94) & -.24(-2.06) \\ \begin{array}{l}\text { Behavior } \\ \text { Drug Use }\end{array} & -.31 & -.13 & 0 & -.18(-1.84) & -.18(-1.84)\end{array}$

Table 4. Effect Variables on Drug Use and Grades for Males 
Figure 1. Path Model for Ethnic Identity, Confidence In Not Use Drugs, Deviancy, Peer Influence, Drug Use and Academic Achievement for Males and Female Adolescents (females data in italics)

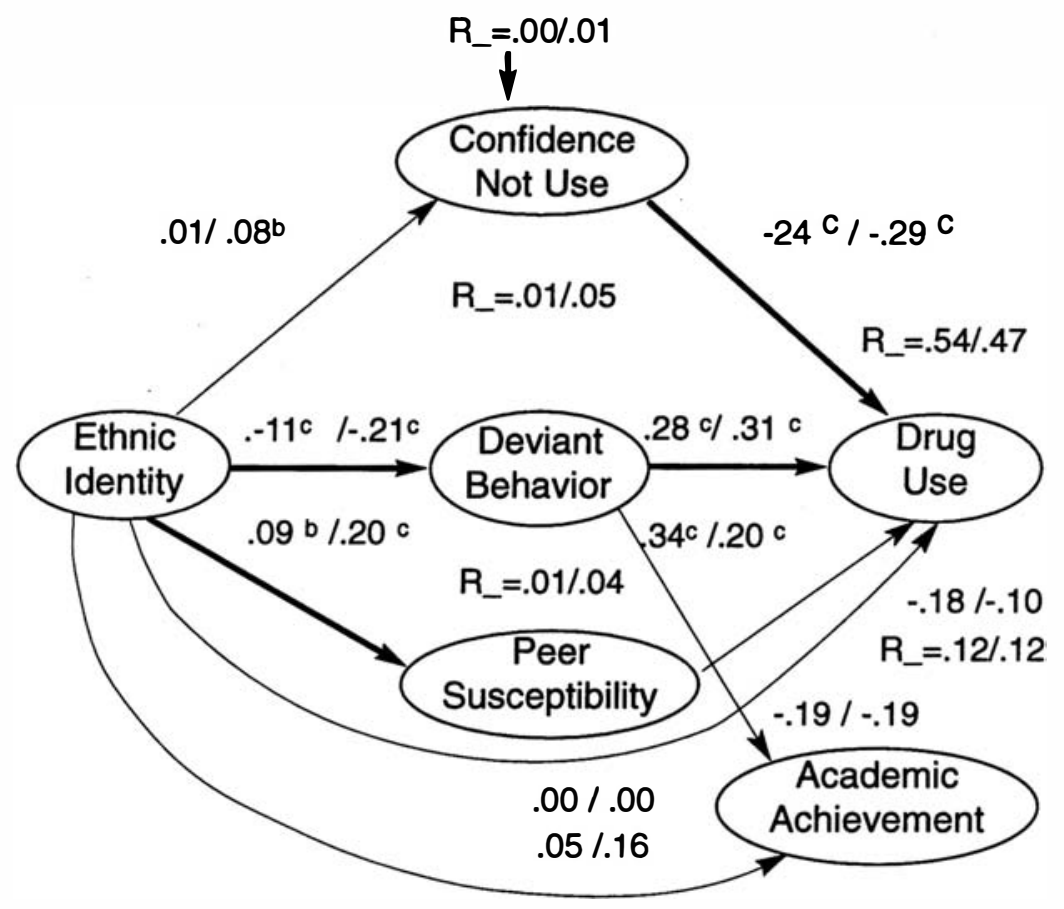

a $t>1.96, p<.05 ;$ b $t>2.57, p<.01 ; c t>3.29, p<.001$

\section{Discussion}

The results of the analyses indicate that for both males and females those with a positive sense of ethnicity are less likely to be involved in deviant activities and are less susceptible to peer influence. This is consistent with Erikson's (1968) assertion that a loss of a sense of identity or "identity confusion" (including ethnic identity) is found in many destructive delinquents. This is also consistent with the observation that many Chicano adolescent gangs have marginal identities or are experiencing an identity crisis (Vigil 1988). Belitz and 
Valdez (1995) reported that many of these youth had few positive role models with strong ethnic identities. The authors propose that any diversion program with at-risk youth include a focus on the prosocial and nonviolent aspects of cultural identity.

The finding that the relationship between ethnic identity and substance use is indirect through risk and protective factors related to substance use rather than direct is consistent with results reported by others (Felix-Ortiz and Newcomb 1995). However other studies have reported a direct relationship between ethnicity and substance use among Hispanic females (Oetting and Beauvais 1990-91) and Puerto Rican male adolescents (Sommers et al. 1993). Some of this discrepancy may be due to variations in models and variables included in the research, age, and ethnic group differences and the regional context of ethnicity. However all of these studies reaffirm the importance of understanding the role of ethnic identity in substance use research.

Ethnic identity was also found to be related to academic achievement, mainly for females. It may be that identity formation for females is different than that for males particularly in relation the schooling experience. For example the development of identity for females seems to include both interpersonal and intrapersonal identity development, whereas males appear to develop mainly intrapersonal identity (Lytle, Bakken, and Romig 1997). These findings suggest that it is important to examine how the education system may influence the connection between ethnic identity development and academic achievement for males and females.

Deviancy and drugs-For both males and females deviant behavior was significantly related to substance use (as well as to academic achievement). This is consistent with previous research with delinquency and substance use among adolescents (Wills et al. 1996) as well as between delinquency and academic achievement (Reyes and Jason 1993). Even though females tend to be less involved in deviant behavior and substance use than males, the strength of association between deviancy and drug use is similar for both genders. However the weaker link between the ethnic identity and deviancy among males compared to females may be due to the tendency of 
males to be reinforced for sex-typed behaviors such as aggression (Archer 1992).

Confidence to not use substances-Self-efficacy theory has generally been applied to smoking and to alcohol use rather than to other drugs. Thus this study provides valuable information on this topic and is also one of the first attempts at using the "confidence in not using drugs" scale with Mexican American adolescents. The significant and somewhat similar relationship between self-efficacy and drug use for both males and females implies that this construct may be similar for both genders. This finding reaffirms the importance of resistance self-efficacy training in substance abuse prevention developed by other researchers (Ellickson, Bell, and McGuigan 1993). However these dynamics needs further exploration with implication for prevention programs to include efforts aimed at common underlying factors related to deviant behavior and substance use that may also be related to self-efficacy (Huizinga et al. 1993).

Drug Use and Academic Achievement-The non-significant relationship between drug use and academic achievement may be due in part to the inclusion of the other risk and protective factors in the equation. A weak relationship has also been observed by Evans and Skaeger (1992) who have stated that a significant proportion of the variance in achievement remains unaccounted for by measures of substance use. Some of this variance is evident in the number of academically successful students using drugs and poor performing students with no drug use reported in previous research (Codina et al. 1998). However future studies need to distinguish between substance use and substance abuse, meaning that abuse negatively impacts the personal life of the individual.

Conclusions-These findings suggest that for Mexican American adolescents issues of ethnic identity development are linked to risk and protective factors related to substance abuse and academic achievement. The salience and dynamics of these issues may also vary by gender. Further research is needed in order to identify the specificity and commonality of these issues for males and females. Furthermore as Erikson (1968) reminds us:

...identity formation, while being 'critical' in youth is 
really a generation issue. So we must not overlook a certain abrogation of responsibility on the part of the older generation in providing those forceful ideas which must antecede identity formation in the next generation-if only so that youth can rebel against a well-defined set of older values. (Italics in the original)(29-30).

This identity formation is, of course, more complicated with minority status youth, since they have to contend with both the values from their own ethnic group as well as the values from the dominant culture. They also have to contend with the additional stressor of being a member of an historically oppressed minority ethnic group.

These concepts reflect complex historical and socio-psychological dynamics that we are just beginning to understand. Future comprehensive prevention and intervention programs aimed at decreasing substance use and increasing academic achievement need to starts addressing these issues in a comprehensive manner working at the individual, the group, and community-school level.

This research was partially supported by the National Institute on Drug Abuse (NIDA) grants DA07234-06 to the Hispanic Research Center, The University of Texas at San Antonio, Texas.

\section{References}

Archer, S. L. 1992. "A feminist's approach to identity research." Adolescent Identity Formation, ed. G. R. Adams, T. P. Gullotta, and R. Montemayor. Newbury Park, CA: Sage Publications.

Beauvais, F., E.L. Chavez, E. R. Oetting, J. L. Deffenbacher, and G. R. Cornell. 1996. "Drug use, violence, and victimization among White American, Mexican American, and American Indian dropouts, students with academic problems, and students in good academic standing." Journal of Counseling Psychology 43: 292-299. 


\section{Ethnic Studies Review Volume 24}

Belitz, J., and D. M. Valdez. 1995. "Clinical issues in the treatment of Chicano male gang youths." Hispanic Psychology: Critical Issues in Theory and Research, ed. A. M. Padilla. Thousand Oaks: Sage Publications.

Brook, J. S., M. Whiteman, E. B., P.T. Win, and M.D. Gursen. 1998. "Drug use among Puerto Ricans: Ethnic identity as a protective factor." Hispanic Journal of Behavioral Sciences 20(2): 241-254.

Chavez, E. L., R. Edwards, and E. R. Oetting. 1989. "Mexican American and White American School dropout's drug use, health status, and involvement in violence." Public Health Reports 104, (6): 594-604.

Cheung, Y. W. 1991. "Overview: Sharpening the focus on ethnicity." International Journal of Addictions 25, 573-579.

Codina, G. E., and F. Montalvo. 1994. "Chicano phenotype and depression." Hispanic Journal of Behavioral Sciences 16: 296306.

Codina, G. E., Z. Yin, D. S. Katims, and J. T. Zapata. 1998. "Marijuana use and academic achievement among Mexican American school-age students: Underlying psychosocial and behavioral characteristics." Journal of Child \& Adolescent Substance Abuse 7 (3): 79-96.

Ellickson, P. L., R. M. Bell, and K. McGuigan. 1993. "Preventing adolescent drug use: Long-term results of a junior high program." American Journal of Public Health 83: 856-861.

Erikson, E. H. (1968). Identity: Youth and Crisis. (1st ed.). New York: W. W. Norton \& Company.

Evans, W. P. and R. Skager. 1992. "Academically successful drug users: An oxymoron?" Journal of Drug Education 22: 353-365.

Fagan, J., J. G. Weis, and Y. T. Cheng, 1990. "Delinquency and 
substance use among inner-city students." Journal of Drug Issues 20(3): 351-402.

Felix-Ortiz, M., and M. D. Newcomb. 1995. "Cultural identity and drug use among Latino and Latina adolescents." Drug Abuse Prevention with Multi-ethnic Youth, ed. G. J. Botvin, S. Schinke, and M. A. Orlandi. Thousand Oaks, CA: Sage Publications.

Frey, W. H., and R. Farley. 1996. "Latino, Asian, and black segregation in U.S. metropolitan areas: Are multiethnic metros different?" Demography 33(1): 35-90.

Hays, R. D., and P. L. Ellickson. 1990. "How generalizable are adolescents' beliefs about pro-drug pressures and resistance self-efficacy." Journal of Applied Social Psychology 20(4): 321340.

Horwitz, A. W., and H. R. White. 1987. "Gender role orientations and styles of pathology among adolescents." Journal of Health and Social Behavior 28:158-170.

Huizinga, D., R. Loeber, and T. P. Thornberry. 1993. "Longitudinal study of delinquency, drug use, sexual activity, and pregnancy among children and youth in three cities." Public Health Reports 108(1): 90-96.

Hundelby, J. D., R. A. Carpener, and G. W. Mercer. 1982. "Adolescent drug use and other behaviors." Journal of Child Psychology and Psychiatry 23: 61-68.

Kelloway, E. K. 1998. Using LISREL for Structural Equation Modeling: A Researcher's Guide. Thousand Oaks, CA: Sage Publications.

Khoury, E. L. 1998. “Are girls different? "A developmental perspective on gender differences in risk factors for substance use among adolescents." Drug Use and Ethnicity in Early Adolescence, ed. W. A. Vega, and A. G. Gil. New York: Plenum, 95-123. 


\section{Ethnic Studies Review Volume 24}

Kitano, H. H. L. 1980. Race Relations. (2nd ed.). Englewood Cliffs, NJ: Prentice-Hall.

Lytle, L. J., L. Bakken, and C. Romig. 1997. “Adolescent female identity development." Sex Roles 37(3-4): 175-185.

Matute-Bianchi, M. E. 1989. Situational ethnicity and patterns of school success and failure among Mexican-descent and Japanese-American students in a California high school: An ethnographic analysis. Santa Cruz: University of California Press.

Oetting, E. R., and F. Beauvais. 1990-91. "Orthogonal cultural identification theory: The cultural identification of minority adolescents." The International Journal of the Addictions 25: 655685.

Opland, E. A., K. C. Winters, and R. D. Stinchfield. 1995. "Examining gender differences in drug-abusing adolescents." Psychology of Additive Behaviors, 9: 167-175.

Phinney, J. S., and D. A. Rosenthal, D. A., eds. 1992. Ethnic identity in adolescence: Process, context and outcome. Newbury Park, California: Sage Publications.

Prochaska, J. O., C. C. DiClementi, and J. C. Norcross. 1992. "In search of how people change: applications to addictive behavior." American Psychologist 479: 1102-1114.

Reyes, O., and L.A. Jason. 1993. "Pilot study examining factors associated with academic success for Hispanic high school students." Journal of Youth and Adolescence 22(1): 5770.

Roberts, R., J. Phinney, J., Romero, A., and Y. W. Chen. 1996. "The cross-cultural structure of adolescent ethnic identity." Paper presented at the Society for Research on Adolescence, Boston, Massachusetts. (March 7-10).

Scheier, L. M., and G. J. Botvin. 1996. "Purpose in life, cogni- 
tive efficacy, and general deviance as determinants of drug abuse in urban black youth." Journal of Child \& Adolescent Substance Abuse 5(1): 1-26.

Sommers, I., J. Fagan, and D. Baskin, D. 1993. "Sociocultural influences on the explanation of delinquency for Puerto Rican youths." Hispanic Journal of Behavioral Sciences 15: 36-62.

Vigil, J. D. 1988. "Group processes and street identity: Adolescent Chicago gang members." Ethos 16: 421-45.

Watts, W. D., and L. S. Wright. 1990. "The relationship of alcohol, tobacco, marijuana, and other illegal drug use to delinquency among Mexican American, Black and White adolescent males." Adolescence, 25(97): 171-181.

Wills, T. A., G. McNamara, D. Vaccaro, and A. E. Hirky. 1996. "Escalated substance use: A longitudinal grouping analysis from early to middle adolescence." American Psychological Association 105(2): 166-180.

Yin, Z., D. S. Katims, and J. T. Zapata. 1999. "Participation in Leisure Activities and Involvement in Delinquency by Mexican American Adolescents." Hispanic Journal of Behavioral Research, 21(2): 170-185. 